\title{
Racial Disparities in Breastfeeding Initiation and Duration Among U.S. Infants Born in 2015
}

\author{
Jennifer L. Beauregard, $\mathrm{PhD}^{1,2}$; Heather C. Hamner, $\mathrm{PhD}^{1}$; Jian Chen, $\mathrm{MS}^{1}$; Wendy Avila-Rodriguez, $\mathrm{MPH}^{1}$;
} Laurie D. Elam-Evans, $\mathrm{PhD} ;{ }^{3}$ Cria G. Perrine, $\mathrm{PhD}^{1}$

Surveillance of U.S. breastfeeding duration and exclusivity has historically reported estimates among all infants, regardless of whether they had initiated breastfeeding. These surveillance estimates have consistently shown that non-Hispanic black (black) infants are less likely to breastfeed, compared with other racial/ethnic groups. * Less is known about disparities in breastfeeding duration when calculated only among infants who had initiated breastfeeding, compared with surveillance estimates based on all infants. CDC analyzed National Immunization Survey-Child (NIS-Child) data for infants born in 2015 to describe breastfeeding duration and exclusivity at ages 3 and 6 months among all black and non-Hispanic white (white) infants, and among only those who had initiated breastfeeding. When calculated among all infants regardless of breastfeeding initiation, breastfeeding differences between black and white infants were 14.7 percentage points ( $95 \%$ confidence interval $[C I]=10.7-18.8)$ for any breastfeeding at age 3 months and were significantly different for both any and exclusive breastfeeding at both ages 3 and 6 months. Among only infants who had initiated breastfeeding, the magnitude of black-white differences in breastfeeding rates were smaller. This was most notable in rates of any breastfeeding at 3 months, where the percentage point difference between black and white infants was reduced to $1.2(95 \% \mathrm{CI}=-2.3-4.6)$ percentage points and was no longer statistically significant. Black-white disparities in breastfeeding duration result, in part, from disparities in initiation. Interventions both to improve breastfeeding initiation and to support continuation among black mothers might help reduce disparities.

Breastfeeding has numerous health benefits for infants and mothers. Breastfed infants have reduced risk for ear, respiratory, and gastrointestinal infections and might be less likely to develop asthma, obesity, and diabetes (1). Mothers who breastfeed have a lower risk for developing type 2 diabetes, hypertension, and breast and ovarian cancers (2). U.S. breastfeeding surveillance has consistently demonstrated that rates of breastfeeding initiation, duration, and exclusivity are 10-20 percentage points lower among black infants, compared with white infants. ${ }^{\dagger}$

\footnotetext{
*https://www.cdc.gov/breastfeeding/data/nis_data/rates-any-exclusive-bf-sociodem-2015.htm.

${ }^{\dagger}$ https://www.cdc.gov/breastfeeding/data/nis_data/index.htm.
}

NIS-Child is an ongoing, nationally representative randomdigit-dialed telephone survey of U.S. households of children aged 19-35 months. From 2011 to 2017, the NIS-Child used a dual landline and mobile telephone sample frame. ${ }^{\S}$ Although NIS-Child primarily assesses childhood vaccination coverage, breastfeeding questions were added in 2001 and are the primary data source for U.S. breastfeeding surveillance. Each cross-sectional survey includes children born in 3 different calendar years; for this analysis of infants born in 2015, data from the 2016-2017 surveys were combined, consistent with national surveillance estimates. Landline sample response rates were $55.7 \%$ in 2016 and $51.9 \%$ in 2017 . Mobile telephone sample response rates were $32.1 \%$ in 2016 and $25.0 \%$ in 2017. Children's breastfeeding history and race/ethnicity were reported by their parents or guardians.

Breastfeeding initiation rates were calculated for black and white infants born in 2015. Rates of any breastfeeding and exclusive breastfeeding (defined as only breast milk and no solids, water, or other liquids) at ages 3 and 6 months were calculated for black and white infants using two sets of denominators. The first denominator included all infants of the respective racial/ethnic group regardless of breastfeeding initiation. The second denominator included only infants of the respective racial/ethnic group who had initiated breastfeeding. The absolute percentage point difference in each breastfeeding rate between black and white infants was also estimated (hereafter, black-white difference). Estimates were weighted and accounted for the NIS complex sampling design. Data were analyzed using SAS (version 9.4; SAS Institute) and SUDAAN (version 11.0.3; RTI International).

Black women were more likely than were white women to have incomes $<100 \%$ of the poverty level $(49.3 \%$ versus $17.8 \%)$, to receive Special Supplemental Nutrition Program for Women, Infants, and Children benefits $(78.2 \%$ versus $34.1 \%)$, and to be unmarried (65.5\% versus $23.9 \%)$; they also had less education and were younger (Table 1). In 2015, $69.4 \%$ of black infants initiated breastfeeding, compared with $85.9 \%$ of white infants, a difference of 16.5 percentage points $(\mathrm{p}<0.05)$ (Table 2).

Among all infants, black infants had a significantly lower rate of any breastfeeding at age 3 months $(58.0 \%)$ than did white

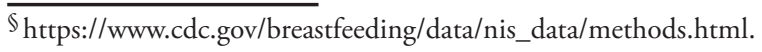


TABLE 1. Demographic characteristics of non-Hispanic white and non-Hispanic black infants born in 2015 included in national prevalence estimates of breastfeeding initiation and duration at ages 3 and 6 months - National Immunization Survey-Child, United States, 2016-2017*

\begin{tabular}{|c|c|c|c|c|}
\hline \multirow[b]{2}{*}{ Characteristic } & \multicolumn{2}{|c|}{ Non-Hispanic white $(n=9,907)$} & \multicolumn{2}{|c|}{ Non-Hispanic black $(n=1,607)$} \\
\hline & No. & $\%(95 \% \mathrm{Cl})^{\dagger}$ & No. & $\%(95 \% \mathrm{Cl})^{\dagger}$ \\
\hline \multicolumn{5}{|l|}{$\%$ of poverty level ${ }^{\S}$} \\
\hline$<100$ & 1,312 & $17.8(16.5-19.1)$ & 635 & $49.3(45.5-53.1)$ \\
\hline 100-199 & 1,703 & $18.7(17.4-20.0)$ & 366 & $21.0(18.2-23.8)$ \\
\hline 200-399 & 2,909 & $27.9(26.5-29.3)$ & 327 & $16.1(13.7-18.4)$ \\
\hline $400-599$ & 1,967 & $17.7(16.5-19.0)$ & 110 & $5.8(4.3-7.3)$ \\
\hline$\geq 600$ & 2,016 & $17.9(16.6-19.3)$ & 169 & $7.8(5.2-10.4)$ \\
\hline \multicolumn{5}{|l|}{ Recipient of WIC } \\
\hline Yes & 2,723 & $34.1(32.5-35.8)$ & 1,137 & $78.2(75.5-80.9)$ \\
\hline No, but eligible & 836 & $9.0(8.1-9.8)$ & 107 & $6.8(5.0-8.5)$ \\
\hline Ineligible & 6,298 & $56.9(55.2-58.6)$ & 356 & $15.0(12.8-17.2)$ \\
\hline \multicolumn{5}{|l|}{ Mother's education } \\
\hline Less than high school diploma or GED & 460 & $7.4(6.3-8.4)$ & 199 & $16.2(12.7-19.7)$ \\
\hline High school diploma or GED & 1,394 & $20.2(18.8-21.6)$ & 391 & $32.2(28.5-35.8)$ \\
\hline Some college & 2,435 & $23.4(22.0-24.8)$ & 491 & $26.3(23.2-29.4)$ \\
\hline College graduate & 5,618 & $49.1(47.4-50.7)$ & 526 & $25.3(22.3-28.3)$ \\
\hline \multicolumn{5}{|l|}{ Mother's age group (yrs) } \\
\hline$<20$ & 70 & $1.1(0.7-1.5)$ & 40 & $2.8(1.6-4.0)$ \\
\hline $20-29$ & 2,943 & $34.4(32.8-36.1)$ & 679 & $45.2(41.4-49.0)$ \\
\hline$\geq 30$ & 6,894 & $64.5(62.8-66.1)$ & 888 & $52.0(48.2-55.8)$ \\
\hline \multicolumn{5}{|l|}{ Mother's marital status } \\
\hline Married & 8,097 & $76.1(74.6-77.7)$ & 682 & $34.5(31.1-37.8)$ \\
\hline Unmarried & 1,810 & $23.9(22.3-25.4)$ & 925 & $65.5(62.2-68.9)$ \\
\hline
\end{tabular}

Abbreviations: GED = general educational development certificate; WIC = Special Supplemental Nutrition Program for Women, Infants, and Children .

* Based on National Immunization Survey-Child data from survey years 2016-2017, among infants born in 2015.

+ Statistics in this table are based on participants who responded to questions about any breastfeeding at ages 3 and 6 months $(N=11,514)$. Sample sizes are slightly smaller for participants who also responded to questions about exclusive breastfeeding at ages 3 and 6 months.

$\S$ Ratio of self-reported family income to the poverty threshold value defined by the U.S. Census Bureau.

" Sample sizes for the proportions of participants receiving WIC are slightly smaller due to missing data on WIC status.

TABLE 2. Breastfeeding initiation and duration at ages 3 and 6 months* among non-Hispanic black and non-Hispanic white infants born in 2015 - National Immunization Survey-Child, United States, 2016-2017 ${ }^{\dagger}$

\begin{tabular}{|c|c|c|c|c|c|c|c|c|c|c|}
\hline \multirow{3}{*}{$\begin{array}{l}\text { Breastfeeding } \\
\text { indicator }\end{array}$} & \multicolumn{5}{|c|}{ All infants } & \multicolumn{5}{|c|}{ Infants who had initiated breastfeeding } \\
\hline & \multicolumn{2}{|c|}{ Non-Hispanic white } & \multicolumn{2}{|c|}{ Non-Hispanic black } & \multirow{2}{*}{$\begin{array}{l}\begin{array}{c}\text { Percentage point } \\
\text { difference }^{\S}\end{array} \\
\%(95 \% \mathrm{Cl})\end{array}$} & \multicolumn{2}{|c|}{ Non-Hispanic white } & \multicolumn{2}{|c|}{ Non-Hispanic black } & \multirow{2}{*}{$\begin{array}{c}\begin{array}{c}\text { Percentage point } \\
\text { difference }\end{array} \\
\%(95 \% \mathrm{Cl})\end{array}$} \\
\hline & No. & $\%(95 \% \mathrm{Cl})$ & No. & $\%(95 \% \mathrm{Cl})$ & & No. & $\%(95 \% \mathrm{Cl})$ & No. & $\%(95 \% \mathrm{Cl})$ & \\
\hline $\begin{array}{l}\text { Initiated } \\
\text { breastfeeding }\end{array}$ & 9,907 & $85.9(84.7$ to 87.1$)$ & 1,607 & $69.4(65.9$ to 73.0$)$ & $16.5(12.7 \text { to } 20.2)^{9}$ & 8,729 & $\mathrm{~N} / \mathrm{A}$ & 1,159 & $\mathrm{~N} / \mathrm{A}$ & N/A \\
\hline $\begin{array}{l}\text { Any } \\
\text { breastfeeding } \\
\text { at age } 3 \text { mos }\end{array}$ & 9,907 & 72.7 (71.2 to 74.2$)$ & 1,607 & $58.0(54.2$ to 61.7$)$ & $14.7(10.7 \text { to } 18.8)^{9}$ & 8,729 & 84.7 (83.4 to 85.9$)$ & 1,159 & 83.5 (80.3 to 86.7$)$ & $1.2(-2.3$ to 4.6$)$ \\
\hline $\begin{array}{l}\text { Exclusive } \\
\text { breastfeeding } \\
\text { through age } \\
3 \text { mos }\end{array}$ & 9,537 & $53.0(51.4$ to 54.7$)$ & 1,573 & 36.0 (32.2 to 39.7$)$ & $17.0(12.9 \text { to } 21.2)^{9}$ & 8,359 & 62.2 (60.5 to 63.9) & 1,125 & 52.3 (47.8 to 56.9 ) & $9.9(5.0 \text { to } 14.7)^{9}$ \\
\hline $\begin{array}{l}\text { Any } \\
\text { breastfeeding } \\
\text { at age } 6 \text { mos }\end{array}$ & 9,907 & $62.0(60.4$ to 63.6$)$ & 1,607 & 44.7 (40.9 to 48.5 ) & $17.3(13.1 \text { to } 21.4)^{9}$ & 8,729 & 72.2 (70.6 to 73.8$)$ & 1,159 & $64.4(60.2$ to 68.6$)$ & $7.8(3.3 \text { to } 12.3)^{9}$ \\
\hline $\begin{array}{l}\text { Exclusive } \\
\text { breastfeeding } \\
\text { through age } \\
6 \text { mos }\end{array}$ & 9,537 & 29.5 (28.0 to 31.1$)$ & 1,573 & 17.2 (14.1 to 20.2$)$ & $12.4(8.9 \text { to } 15.8)^{9}$ & 8,359 & 34.7 (32.9 to 36.4$)$ & 1,125 & 25.0 (20.8 to 29.2 ) & $9.7(5.1 \text { to } 14.2)^{9}$ \\
\hline
\end{tabular}

Abbreviations: $\mathrm{Cl}=$ confidence interval; $\mathrm{N} / \mathrm{A}=$ not applicable.

* Breastfeeding initiation was determined according to participant's response to the question "Was [child] ever breastfed or fed breast milk?" Breastfeeding duration was determined according to participant's response to the question "How old was [child's name] when [child's name] completely stopped breastfeeding or being fed breast milk?" Exclusive breastfeeding was defined as only breast milk (no solids, no water, and no other liquids). To assess the duration of exclusive breastfeeding, participants were asked two questions about age: 1) "How old was [child's name] when he/she was first fed formula?" and 2) "How old was [child's name] when he/she was first fed anything other than breast milk or formula?" (This includes juice, cow's milk, sugar water, baby food, or anything else that [child] might have been given, even water).

† Based on National Immunization Survey-Child data from survey years 2016-2017, among infants born in 2015.

$\S$ Differences in breastfeeding rates between non-Hispanic black and non-Hispanic white infants.

I Differences in breastfeeding rates between non-Hispanic black and non-Hispanic white infants are statistically significant ( $p<0.05$, two-sample test of proportions). 
infants (72.7\%); at age 6 months, the rates were $44.7 \%$ among black infants and $62.0 \%$ among white infants $(\mathrm{p}<0.05)$. Rates for exclusive breastfeeding at age 3 months were $36.0 \%$ among black infants and $53.0 \%$ among white infants; at age 6 months, the rates were $17.2 \%$ among black infants and $29.5 \%$ among white infants $(\mathrm{p}<0.05)$ (Table 2$)$. At age 3 months, black-white differences were 14.7 percentage points for any breastfeeding $(95 \% \mathrm{CI}=10.7-18.8)$ and 17.0 percentage points for exclusive breastfeeding $(95 \% \mathrm{CI}=12.9-21.2)$. At age 6 months, blackwhite differences were 17.3 percentage points for any breastfeeding $(95 \% \mathrm{CI}=13.1-21.4)$ and 12.4 percentage points for exclusive breastfeeding (95\% CI = 8.9-15.8) (Table 2).

Among only infants who had initiated breastfeeding, the magnitude of black-white differences in any and exclusive breastfeeding rates were smaller (Table 2). This was most notable in rates of any breastfeeding at 3 months, where the percentage point difference between black and white infants was reduced from $14.7(95 \% \mathrm{CI}=10.7-18.8)$ to $1.2(95 \%$ $\mathrm{CI}=-2.3-4.6)$ percentage points; this difference was no longer statistically significant. The black-white difference in exclusive breastfeeding at age 3 months was reduced from 17.0 percentage points $(95 \% \mathrm{CI}=12.9-21.2)$ to 9.9 percentage points $(95 \% \mathrm{CI}=5.0-14.7)$, in any breastfeeding at 6 months from 17.3 percentage points $(95 \% \mathrm{CI}=13.1-21.4)$ to 7.8 percentage points $(95 \% \mathrm{CI}=3.3-12.3)$, and in exclusive breastfeeding at age 6 months from 12.4 percentage points (8.9-15.8) to 9.7 percentage points $(95 \% \mathrm{CI}=5.1-14.2)$.

\section{Discussion}

Surveillance of U.S. breastfeeding duration and exclusivity, including monitoring for Healthy People 2020 objectives, reports estimates among all infants, regardless of whether they had initiated breastfeeding. The findings in this report demonstrate that differences between black and white infants in any and exclusive breastfeeding at ages 3 and 6 months are caused, in part, by racial/ethnic differences in breastfeeding initiation. Interventions to improve breastfeeding initiation and support continuation among black mothers might be important to closing the black-white gap in duration.

Black mothers disproportionately experience a number of barriers to breastfeeding, including lack of knowledge about breastfeeding; lack of peer, family, and social support; insufficient education and support from health care settings; and concerns about navigating breastfeeding and employment (3). Subjective norms, or perceptions of approval from others who are important to the person (e.g., family members), are important drivers of breastfeeding behaviors, particularly

\footnotetext{
https:/www.healthypeople.gov/2020/topics-objectives/topic/maternal-infantand-child-health/objectives.
}

among black women (3). Increasing interpersonal support for breastfeeding might help increase breastfeeding initiation and duration among black women, who might lack breastfeeding role models in their social networks and be more likely to face negative perceptions of breastfeeding among their peers and communities $(3,4)$. For example, peer counseling might increase breastfeeding initiation and duration among black mothers (3).

In the United States, the rate of implementation of evidencebased maternity care practices supportive of breastfeeding is lower among maternity care facilities in neighborhoods with larger black populations (5). Hospitals' use of such practices, which include helping women initiate breastfeeding within the first hour of birth and not providing breastfeeding infants with infant formula without a medical indication, increases rates of breastfeeding initiation, duration, and exclusivity (G). A recent analysis indicated that making improvements in these practices among maternity care facilities in four southern states reduced black-white disparities in breastfeeding initiation (7).

Returning to work is another major barrier to breastfeeding initiation and continuation, particularly for black women (3). A woman's plans for returning to work are associated with her intention to breastfeed; specifically, women planning to return to work before 12 weeks postpartum, planning to work fulltime, or both were less likely to intend to exclusively breastfeed, compared with women planning to return to work after 12 weeks postpartum, planning to work part-time, or both (8). Black women, especially those with a low income, return to work earlier than do women in other racial/ethnic groups and are more likely to experience challenges to breastfeeding or expressing milk, including inflexible work hours (9). Policies that enable taking paid leave after giving birth, flexible work schedules, and support for breastfeeding or expressing milk at work might help improve breastfeeding intention, initiation, and duration. ${ }^{* *}$

The findings in this report are subject to at least three limitations. First, response rates averaged $53.8 \%$ for the landline sample and $28.6 \%$ for the mobile telephone sample; further, households without a telephone are not represented. The possibility exists that selection bias occurs even after adjusting weights for nonresponse and noncoverage. Second, maternal reports of breastfeeding behaviors could be subject to recall bias because mothers reported these behaviors when their children were aged 19-35 months and to social desirability bias because of a desire to provide socially acceptable responses. However, maternal recall of breastfeeding behavior has been found to be valid and reliable, especially when recalled within 3 years (10). Finally, although this report focuses only on black-white

** https://www.cdc.gov/breastfeeding/resources/calltoaction.htm. 


\section{Summary}

What is already known on this topic?

Rates of breastfeeding duration and exclusivity, calculated for all infants regardless of whether they had initiated breastfeeding, are lower among black infants than among white infants.

What is added by this report?

Among infants who had initiated breastfeeding, differences between black infants and white infants in any and exclusive breastfeeding at ages 3 and 6 months were smaller but still present.

What are the implications for public health practice?

Increasing rates of breastfeeding initiation and supporting continuation of breastfeeding among black women might help reduce disparities in breastfeeding duration. Strategies might include improving peer and family support, access to evidencebased maternity care, and employment support.

breastfeeding differences, lower rates of breastfeeding duration and exclusivity among Hispanic infants, compared with nonHispanic white infants, have been documented (3). However, because Hispanic and white infants have similar rates of breastfeeding initiation, the methods applied in this report did not affect estimates of breastfeeding duration and exclusivity.

Breastfeeding provides optimal nutrition to infants and provides health benefits for both infants and mothers, and CDC works to increase breastfeeding rates among all mothers in the United States. In order to address disparities in breastfeeding duration, continued efforts are needed to increase rates of breastfeeding initiation and support continuation of breastfeeding among black women. Closing the black-white gap in breastfeeding duration might require efforts of multiple groups. Families, hospitals, and employers can help black women initiate and continue breastfeeding, thereby providing their infants with optimal nutrition.

\section{Acknowledgments}

Katherine Shealy, Division of Nutrition, Physical Activity, and Obesity, National Center for Chronic Disease Prevention and Health Promotion, CDC; Kelley Scanlon, Office of Policy Support, Food and Nutrition Service, U.S. Department of Agriculture, Washington, D.C.
Corresponding author: Jennifer L. Beauregard, uzy2@cdc.gov, 404-498-5337.

${ }^{1}$ Divison of Nutrition, Physical Activity, and Obesity, National Center for Chronic Disease Prevention and Health Promotion, CDC; ${ }^{2}$ Epidemic Intelligence Service, CDC; ${ }^{3}$ Immunization Services Division, National Center for Immunization and Respiratory Diseases, CDC.

All authors have completed and submitted the International Committee of Medical Journal Editors form for disclosure of potential conflicts of interest. No potential conflicts of interest were disclosed.

\section{References}

1. Ip S, Chung M, Raman G, et al. Breastfeeding and maternal and infant health outcomes in developed countries. Evid Rep Technol Assess (Full Rep) 2007;153:1-186.

2. Feltner C, Weber R, Stuebe A, Grodensky C, Orr C, Viswanathan M. Breastfeeding programs and policies, breastfeeding uptake, and maternal health outcomes in developed countries. Comparative effectiveness review no. 210. Rockville, MD: US Department of Health and Human Services, Agency for Healthcare Research and Quality; 2018. https:// www.ncbi.nlm.nih.gov/books/NBK525106

3. Jones KM, Power ML, Queenan JT, Schulkin J. Racial and ethnic disparities in breastfeeding. Breastfeed Med 2015;10:186-96. https:// doi.org/10.1089/bfm.2014.0152

4. Louis-Jacques A, Deubel TF, Taylor M, Stuebe AM. Racial and ethnic disparities in U.S. breastfeeding and implications for maternal and child health outcomes. Semin Perinatol 2017;41:299-307. https://doi. org/10.1053/j.semperi.2017.04.007

5. Lind JN, Perrine CG, Li R, Scanlon KS, Grummer-Strawn LM. Racial disparities in access to maternity care practices that support breastfeeding-United States, 2011. MMWR Morb Mortal Wkly Rep 2014;63:725-8.

6. Pérez-Escamilla R, Martinez JL, Segura-Pérez S. Impact of the babyfriendly hospital initiative on breastfeeding and child health outcomes: a systematic review. Matern Child Nutr 2016;12:402-17. https://doi. org/10.1111/mcn. 12294

7. Merewood A, Bugg K, Burnham L, et al. Addressing racial inequities in breastfeeding in the southern United States. Pediatrics 2019;143:e20181897. https://doi.org/10.1542/peds.2018-1897

8. Mirkovic KR, Perrine CG, Scanlon KS, Grummer-Strawn LM. In the United States, a mother's plans for infant feeding are associated with her plans for employment. J Hum Lact 2014;30:292-7. https://doi. org/10.1177/0890334414535665

9. Johnson A, Kirk R, Rosenblum KL, Muzik M. Enhancing breastfeeding rates among African American women: a systematic review of current psychosocial interventions. Breastfeed Med 2015;10:45-62. https://doi. org $/ 10.1089 / \mathrm{bfm} .2014 .0023$

10. Li R, Scanlon KS, Serdula MK. The validity and reliability of maternal recall of breastfeeding practice. Nutr Rev 2005;63:103-10. https://doi. org/10.1111/j.1753-4887.2005.tb00128.x 